Bài báo khoa học

\title{
Nghiên cứu xu thế biến đổi và dự tính khí hậu trong tương lai cho tỉnh Ninh Thuận
}

\author{
Nguyễn Hoàng Tuấn ${ }^{*}$, Trương Thanh Cảnh² \\ ${ }^{1}$ Trường ĐH Khoa học Tự nhiên, ĐHQG.HCM-VN; nhtuansg@gmail.com \\ 2 Trường ĐH Khoa học Tự nhiên, ĐHQG.HCM-VN; ttcanh@hcmus.edu.vn \\ * Tác giả liên hệ: nhtuansg@gmail.com; Tel.: +84-937919194 \\ Ban Biên tập nhận bài: 04/11/2020; Ngày phản biện xong: 25/12/2020; Ngày đăng bài:
} $25 / 2 / 2021$

Tóm tắt: Mục tiêu của nghiên cứu là phân tích và dự tính xu thế biến đổi các yếu tố khí hậu trong tương lai của tỉnh Ninh Thuận. Phương pháp kiểm định phi tham số sẽ được sử dụng trong nghiên cứu này bằng hai phân tích Mann-Kendall và Theil-Sen. Kết quả nghiên cứu đã cho thấy nhiệt độ trung bình có xu hướng tăng với trung bình năm tăng $0,01{ }^{\circ} \mathrm{C}$, lượng mưa trung bình năm tăng thêm $11,01 \mathrm{~mm}$, độ bốc thoát hơi tiềm năng tăng $0,013 \mathrm{~mm}$, và độ ẩm trung bình năm giảm $0,01 \%$. Bên cạnh đó, kết quả dư tính xu thế so với giai đoạn nghiên cứu cho thấy đến cuối thế kỷ 21 nhiệt độ trung bình năm tăng $0,8{ }^{\circ} \mathrm{C}$, lượng mưa tăng trên $880,8 \mathrm{~mm}$, lượng bốc thoát hơi tiềm năng tăng $9,04 \mathrm{~mm}$, và độ ẩm giảm $1,0 \%$. Kết quả nghiên cứu đã đóng góp thêm vào cơ sở dữ liệu cho áp dụng kiểm định phi tham số trong lĩnh vực quản lí Tài nguyên và Môi trường. Cùng với đó, nghiên cứu đã cung cấp thêm cho địa phương một công cụ nghiên cứu về xu thế biến đổi đặc điểm khí hậu, giúp các cơ quan, tổ chức hiểu hơn về đặc điểm khí hậu để từ đó có những chiến lược, giải pháp để thích ứng và giảm nhẹ tác động của hạn hán đến kinh tế-xã hội của địa phương.

Từ khóa: Nhiệt độ; Lượng mưa; Độ ẩm; Bốc thoát hơi tiềm năng; Mann-Kendall; TheilSen.

\section{Mở đầu}

Ninh Thuận là một tỉnh thuộc vùng Nam Trung Bộ của Việt Nam, với phía Đông giáp Biển Đông, phía Bắc giáp với tỉnh Khánh Hòa, phía Tây giáp với tỉnh Lâm Đồng, và phía Nam giáp với tỉnh Bình Thuận (Hình 1). Ninh Thuận được nhận định là một tỉnh khô hạn nhất cả nước với điều kiện Khí hậu Thủy văn khắc nghiệt [1-4], đồng thời đây cũng là nơi có nguy cơ sa mạc hóa và tài nguyên đất có nguy cơ suy thoái ở mức độ nghiêm trọng ở Việt Nam [1,5]. Với lượng mưa trung bình năm ghi nhận được tại Ninh Thuận rất thấp vào khoảng $750 \mathrm{~mm}$, số giờ nắng trong năm rất cao khoảng 2700-2800 giờ, lượng bốc hơi nước tiềm năng khá cao vào khoảng $1500 \mathrm{~mm} /$ năm là những nguyên nhân gây ra hạn hán ở Ninh Thuận [6]. Để nghiên cứu về đặc điểm khí hậu thông thường sẽ nghiên cứu các yếu tố nhiệt gió, mưa, nắng, ẩm, bốc hơi, và nắng nóng [4]. Tuy nhiên, với mục tiêu nghiên cứu đặc điểm và dự tính tính xu thế biến đổi đặc điểm khí hậu tỉnh Ninh Thuận nên nghiên cứu tập trung một số số yếu có liên quan đến hạn hán như: nhiệt độ, lượng mưa, bốc thoát hơi tiềm năng, và độ ẩm.

\section{Phương pháp nghiên cứu}

\subsection{Dũ liệu nghiên cứu}

Trong nghiên cứu này, tác giả sử dụng dữ liệu nghiên cứu ở trạm Pha Rang. Tuy nhiên, do thời gian quan trắc về lượng mưa, nhiệt độ, và độ ẩm khác nhau nên dữ liệu chuỗi thời 
gian của các yếu tố sẽ không thống nhất. Với nhiệt độ trung bình được lấy từ năm 19932016; Lượng mưa lấy từ 1981 đến năm 2016; Độ ẩm lấy từ 1993-2016; Bốc hơi tiềm năng lấy từ 1986-2016. Số liệu được sử dụng trong nghiên cứu được lấy từ những nguồn có giá trị và độ chính xác cao từ Trung tâm Khí tượng Thủy Văn Quốc Gia, Trung tâm Khí tượng Thủy văn khu vực Ninh Thuận, Niên giám thống kê tỉnh Ninh Thuận. Riêng về số liệu về độ bốc thoát hơi tiềm năng, nghiên cứu đã sử dụng phương pháp Thornthwaite [7], đây cũng là phương pháp được áp dụng phổ biến trên thế giới liên quan đến thu thập dữ liệu về bốc thoát hơi tiềm năng [8-13].

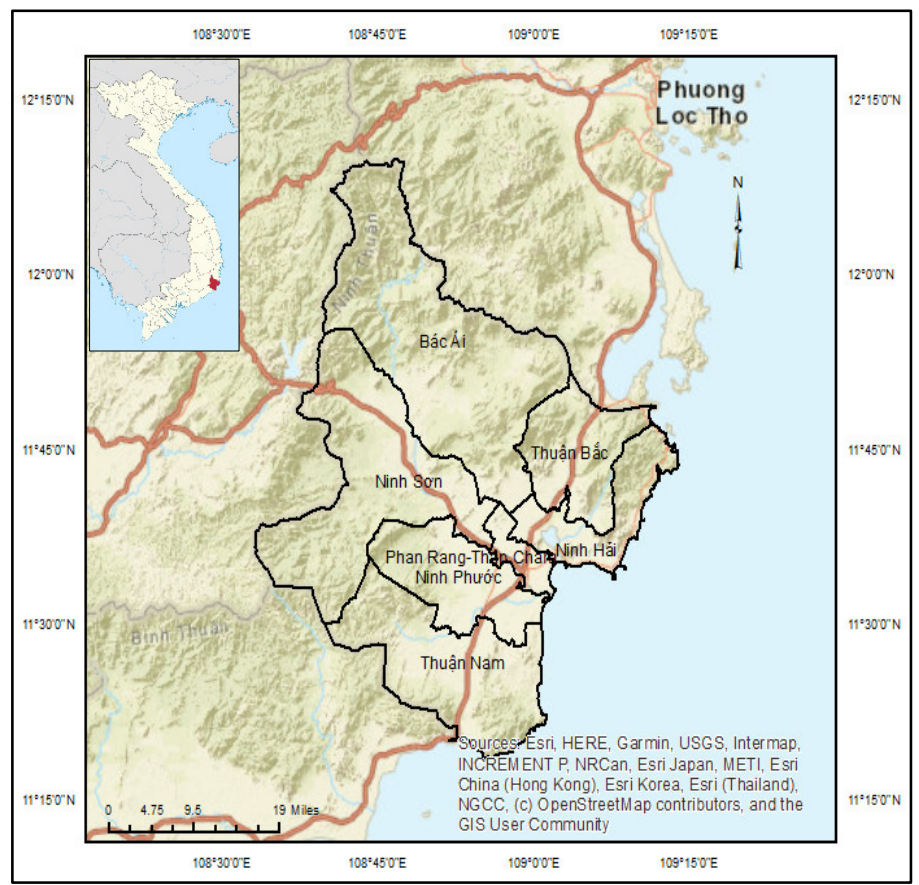

Hình 1. Khu vực nghiên cứu của đề tài.

\subsection{Phưong pháp nghiên cưu}

Để nghiên cứu xu thế và dự tính biến đổi đặc điểm khí hâu tỉnh Ninh Thuận, tác giả sử dụng phương pháp thống kê phi tham số. Trong phân tích phi tham số thì phân tích MannKendall $(\mathrm{MK})$ và độ dốc Theil-Sen $(\mathrm{TS})$ được dụng trong nghiên cứu này. Phân tích $\mathrm{MK}$ và TS [14-17] được ứng dụng trong nhiều lĩnh vực liên quan đến đánh giá xu thế biến đổi và dự tính các giá trị trong một chuỗi dữ liệu thời gian. Trong lĩnh vực Khí tượng và Thủy văn các phân tích này được ứng dụng nhiều trong các nghiên cứu về xu thế biến đổi nhiệt độ, lượng mưa, và hạn hán trên thế giới [18-24]. Tại Việt Nam, phương pháp được sử dụng ngày càng phổ biến trong các nghiên cứu về xu thế biến đổi các yếu tố liên quan đển Khí tượng và Thủy văn [25-28]. Theo đó, phân tích MK được tính theo công thức (1):

$$
S=\sum_{i=1}^{\mathrm{n}-1} \sum_{j=i+1}^{n} \operatorname{sgn}\left(x_{j}-x_{i}\right)
$$

với $\operatorname{Sgn}\left(x_{j}-x_{i}\right)$ được tính theo công thức (2):

$$
\operatorname{Sgn}\left(x_{j}-x_{i}\right)=\left\{\begin{array}{l}
+1 \text { nếu }\left(x_{j}>x_{i}\right) \\
0 \quad \text { nếu }\left(x_{j}=x_{i}\right) \\
-1 \text { nếu }\left(x_{j}<x_{i}\right)
\end{array}\right.
$$


Nếu kết quả tính toán cho ra chỉ số $S$ dương $(S>0)$ thì giá trị tính có xu hướng tăng, ngược lại nếu $\mathrm{S}$ âm $(\mathrm{S}<0)$ thì giá trị tính có xu hướng giảm. Tuy nhiên, cần phải xác định ý nghĩa của xu hướng của giá trị chúng ta phải tính phương sai của $S$ và $n$. Do đó, VAR(S) được tính theo công thức (3):

$$
\operatorname{VAR}(S)=\frac{1}{18}\left[n(n-1)(2 n+5)-\sum_{p=1}^{g} t_{p}\left(t_{p}-1\right)\left(2 t_{p}+5\right)\right]
$$

Để tuân thủ theo luật phân phối chuẩn trung bình 0 , phương sai 1, chỉ số Mann-Kendall (Z ) được tính theo công thức (4):

$$
\begin{array}{r}
Z=\frac{S-1}{[\operatorname{VAR}(S)]^{1 / 2}}, \text { khi } S>0 \\
\mathrm{Z}=0, \text { khi } S=0 \\
Z=\frac{S+1}{[\operatorname{VAR}(S)]^{1 / 2}} \text {, khi } S<0
\end{array}
$$

Và nếu kết quả $Z$ dương $(Z>0)$ thì giá trị cần đánh giá có xu hướng tăng và nếu kết quả $\mathrm{Z}$ âm $(\mathrm{Z}<0)$ thì giá trị cần đánh giá có xu hướng giảm.

Bên cạnh đó, để xác định mức độ tăng hay giảm của giá trị cần phân tích, nghiên cứu cần phân tích thêm độ dốc TS. TS $(\mathrm{Q})$ được tính theo công thức (5):

$$
Q=\frac{x_{i}^{\prime}-x_{i_{\mathrm{i}}}^{\prime}}{i^{\prime}-i} \text { với } \mathrm{i}=1,2,3 \ldots \mathrm{n}
$$

Trong đó $\mathrm{Q}$ là độ dốc giữa hai điểm $x_{i}$ và $x_{i}^{\prime} ; x_{i}^{\prime}$ dữ liệu đo lường tại thời điểm $i^{\prime} ; x_{i}$ dữ liệu đo lường tại thời điểm $i ; i^{\prime}$ thời gian sau thời gian $i$; Ngoài việc tính $\mathrm{Q}$ ra để có được ước tính độ dốc cần phải tính độ dốc trung bình $\left(Q^{\prime}\right)$. Theo đó, $Q^{\prime}$ được tính theo công thức (6):

$$
Q^{\prime}= \begin{cases}Q\left\lceil\frac{N+1}{2}\right\rceil & \text { Nếu } N \text { là lẻ } \\ \frac{Q[N+1]+Q[N+2]}{2} & \text { Nếu } N \text { là chẳn }\end{cases}
$$

Đây là phép thử hai mặt với độ tin cậy $100(1-\alpha) \%$. Kết quả nếu $Q^{\prime}(+)$ dương thì giá trị tăng và nếu giá trị $Q^{\prime}(-)$ thì giá trị đó giảm.

Bên cạnh đó, kết quả dự tính xu thế tăng của nhiệt độ, lượng mưa, độ ẩm, và lượng bốc thoát hơi tiềm năng được tính theo hệ thức (7):

$$
\mathrm{X}_{\mathrm{a}}=\left(\mathrm{TS}_{\mathrm{j}} *\left(\mathrm{Y}_{\mathrm{a}}-\mathrm{Y}_{\mathrm{i}}\right)\right)+\mathrm{Y}_{\mathrm{gt}}
$$

Trong đó $\mathrm{X}$ là $\mathrm{Xu}$ thế; a là năm muốn dự tính; $\mathrm{TS}_{\mathrm{j}}$ là giá trị Theil-Sen trong giai đoạn tính; Ya là năm cần dự tính; $Y_{i}$ là năm được chọn làm chuẩn để dự tính; $Y_{g t}$ là giá trị của năm chuẩn dự tính.

\section{Kết quả và thảo luận}

\section{1. Đặc điểm khi hậu giai đoạn nghiên cưu}

\subsection{1. Đặc điểm về nhiệt độ và lượng mưa}

Nhìn chung trong giai đoạn nghiên cứu, nhiệt độ trung bình ở Ninh Thuận dao động từ $27,1^{\circ} \mathrm{C}$ đến $27,5^{\circ} \mathrm{C}$, và nhiệt độ trung bình cao nhất trong giai đoạn này là $27,6^{\circ} \mathrm{C}$ và thấp nhất là $26,6^{\circ} \mathrm{C}$. Khí hậu ở Ninh Thuận có hai mùa rõ rệt là mùa mưa (tháng 9 đến tháng 11 ) 
và mùa khô (tháng 12 đến tháng 8 ) nên nhiệt độ giữa hai mùa có sự chênh lệch nhau. Vào mùa mưa nhiệt độ trung bình dao động từ $22,6^{\circ} \mathrm{C}$ dến $27,3^{\circ} \mathrm{C}$, trong khi nhiệt độ trung mùa khô cao hơn mùa mưa từ $27,3^{\circ} \mathrm{C}$ đến $27,5^{\circ} \mathrm{C}$ (Hình $2 \mathrm{a}$ ). Bên cạnh đó, Ninh Thuận là một trong những tỉnh có lượng mưa rất thấp với lượng mưa trung bình năm giai đoạn nghiên cứu dao động từ $7,4 \mathrm{~mm}$ đến $115,4 \mathrm{~mm}$. Lượng mưa cũng có sự phân hóa giữa mùa mưa và mùa khô, lượng mưa trung bình giai đoạn nghiên cứu là 157,3 mm trong khi mùa khô có 103,3 $\mathrm{mm}$; vào mùa mưa lượng mưa cao nhất $320 \mathrm{~mm}$ (1981) và thấp nhất là $50 \mathrm{~mm}$ (1982); mùa khô lượng mưa rất thấp, với với lượng mưa thấp nhất là $18 \mathrm{~mm}$ và cao nhất là $269,4 \mathrm{~mm}$ (Hình 2b).

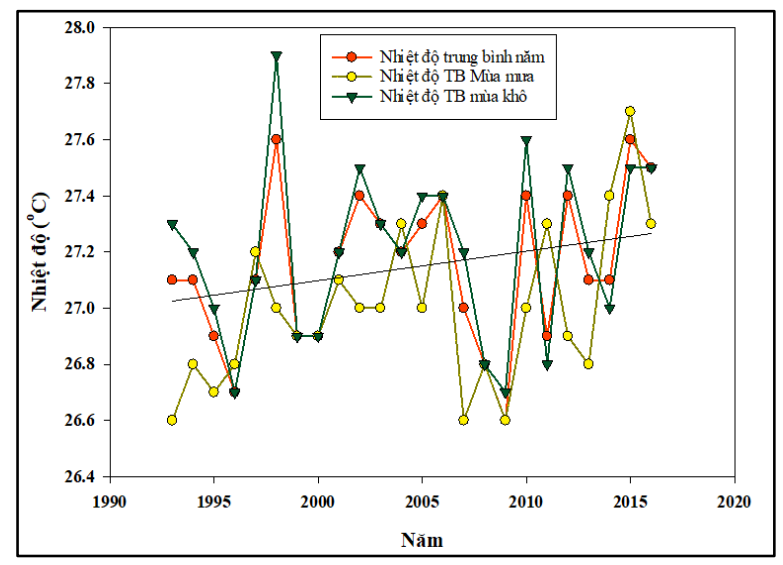

(a)

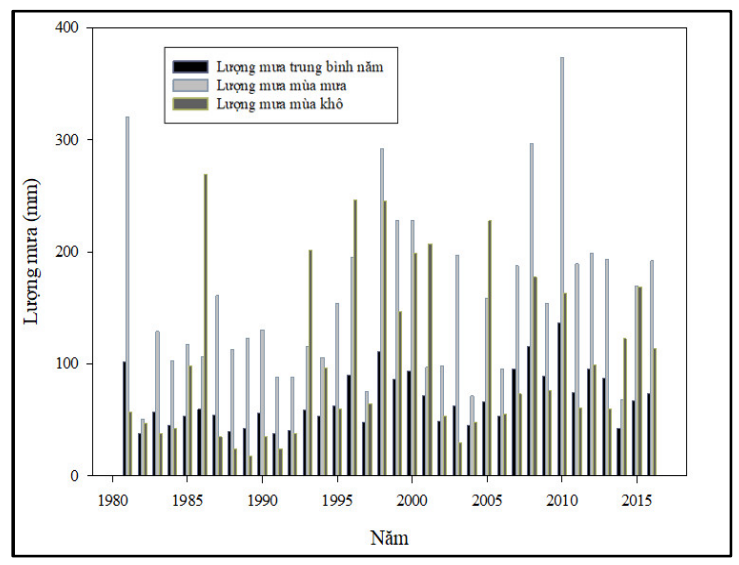

(b)

Hình 2. Đặc trưng nhiệt độ trung bình năm (a) và lượng mưa (b) tại trạm Pha Rang.

\subsection{2. Đặc điểm về độ ẩm và lượng bốc thoát hơi tiềm năng}

Độ ẩm ở Ninh Thuận trong giai đoạn nghiên cứu dao động từ $73 \%$ đến $78 \%$. Phân tích hình $3 \mathrm{a}$ có thể thấy độ ẩm trung bình năm của Ninh Thuận thấp nhất vào khoảng $73,3 \%$, cao nhất $78,6 \%$, với nền ẩm trung bình năm thấp hơn trung bình của mùa mưa và cao hơn trung bình mùa khô; vào mùa mưa độ ẩm tương đối cao với độ ẩm thấp nhất $74,4 \%$ và cao nhất là $82,3 \%$; độ ẩm vào mùa khô dao động từ $72,3 \%$ đến $77,8 \%$ (Hình $3 \mathrm{a}$ ). Lượng bốc thoát hơi tiềm năng ở Ninh Thuận khá cao với trung bình năm luôn trên $140 \mathrm{~mm}$ với lượng bốc hơi dao động từ $142 \mathrm{~mm}$ đển $160 \mathrm{~mm}$. Về lượng bốc thoát nơi tiềm năng trong giai đoạn nghiên cho thấy lượng bốc hơi cao nhất $160,8 \mathrm{~mm}$ và thấp nhất là $140,6 \mathrm{~mm}$. Xét theo mùa thì lượng bốc thoát hơi tiềm năng ở mùa khô cao hơn cả mùa mưa và trung bình năm; Với mùa khô lượng bốc hơi trung bình giai đoạn nghiên cứu đạt $153,8 \mathrm{~mm}$, trong khi mùa mưa lương bốc hơi đạt 135,9 mm và trung bình năm đạt 149,3 mm (Hình 3b). 


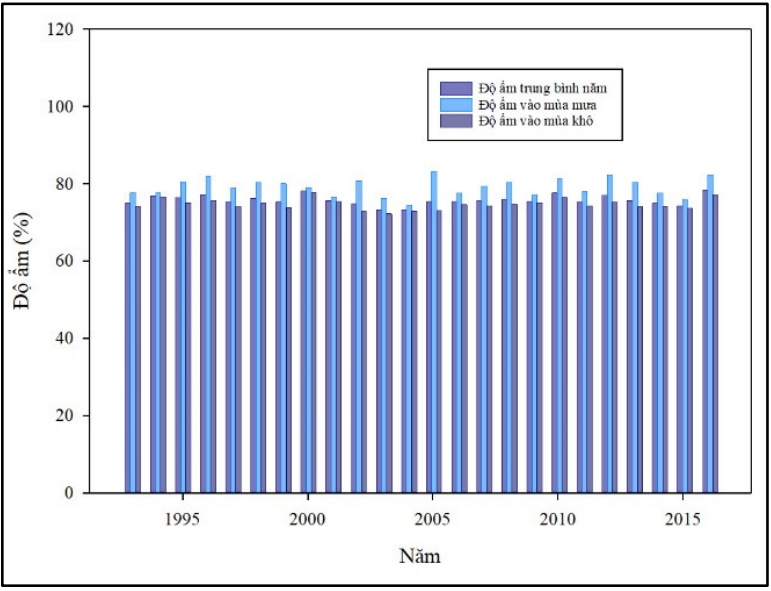

(a)

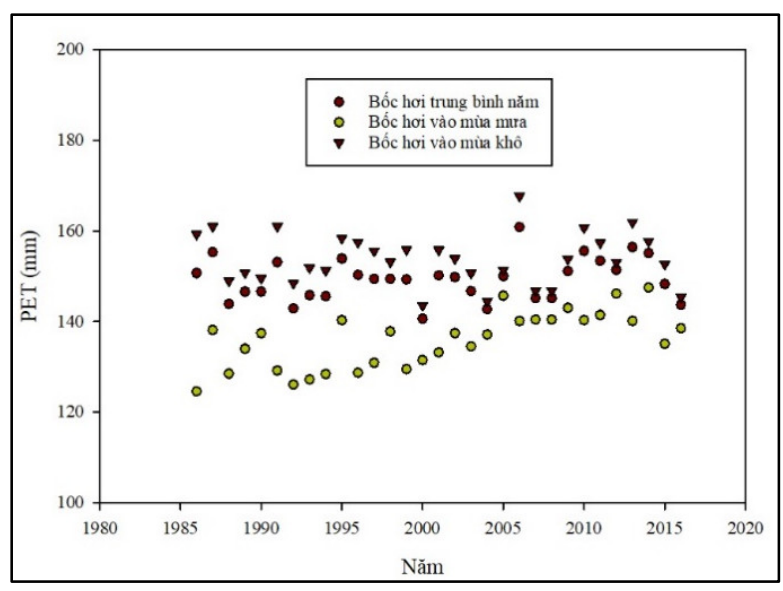

(b)

Hình 3. Biểu đồ thể hiện độ ẩm (a) và lượng bốc thoát hơi (b) hàng năm ở Ninh Thuận.

\subsection{Xu thế biến đổi nhiệt độ, lương mua, độ ẩm, và lương bốc thoát hơ tiềm năng}

\subsubsection{Xu thế biến đổi nhiệt độ trung bình năm}

Kết quả phân tích xu thế cho thấy nhiệt độ trung bình ở Ninh Thuận đang có xu hướng biến đổi theo chiều hướng tăng giảm khác nhau. Kết quả cho thấy trong năm chỉ có tháng 2 và tháng 3 là hai tháng có xu hướng giảm và các tháng còn lại có xu hướng tăng (Bảng 2 ). Cụ thể vào tháng 2 và 3 giá trị $M K$ cho kết quả âm với giá trị lần lượt: giá trị $S$ là -14 và -9 , độ lệch chuẩn $S$ là 40,17 và 40,01 , chỉ số $Z$ là $-0,324,-0,2$, và độ tín cậy là 0,373 và 0,421 . Tuy nhiên, trong hai tháng này, xét về xu thế giảm rõ nét nhất chỉ có tháng 2 còn tháng $3 \mathrm{MK}$ giảm nhưng độ dốc Sen không có. Với tháng 2 độ dốc TS đạt 0,00596 tương đương với nhiệt độ tháng 2 có xu hướng giảm xuống $0,00596^{\circ} \mathrm{C}$, ngược lại vào tháng 3 độ dốc TS cho ra kết quả là 0 . Các tháng còn lại điều tăng với mức tăng nhiệt độ tương ứng độ dốc TS. Cụ thể, vào tháng 1 sẽ tăng $0,00417{ }^{\circ} \mathrm{C} /$ năm, tháng 4 tăng $0,00667{ }^{\circ} \mathrm{C} /$ năm, tháng 5 tăng 0,020 ${ }^{\circ} \mathrm{C} /$ năm, tháng 6 và 7 không tăng, tháng 8 tăng $0,00667^{\circ} \mathrm{C} /$ năm, tháng 9 tăng $0,0248^{\circ} \mathrm{C} /$ năm, tháng 10 tăng $0,0143{ }^{\circ} \mathrm{C} /$ năm, tháng 11 tăng $0,0342{ }^{\circ} \mathrm{C} /$ năm, và tháng 12 tăng $0,0306^{\circ} \mathrm{C} /$ năm (Bảng 2).

Kết quả phân tích xu thế năm cho thấy trong năm nhiệt độ trung bình tăng $0,01^{\circ} \mathrm{C} /$ năm, mức tăng này tương ứng với kết quả tính độ dốc TS là 0,01 ; Giá trị $\mathrm{S}$ của trung bình năm đạt tương đối cao là 43 , độ lệc chuẩn $S$ là 39,72 , chỉ số $Z$ là 1,057 và độ tin cậy $p$-value là 0,145 . Bên cạnh đó, kết quả phân tích $\mathrm{MK}$ và $\mathrm{TS}$ theo các mùa mưa và mùa khô cũng cho thấy xu hướng tăng ở hai mùa này. Theo độ dốc TS nhiệt độ trung bình hai mùa có xu hướng tăng trong đó mùa mưa tăng nhiều hơn mùa khô với $0,0225^{\circ} \mathrm{C} /$ năm so với $0,00833^{\circ} \mathrm{C} /$ năm. Riêng mùa mưa, chỉ số $\mathrm{p}$-value bằng 0,0165 , chỉ số này phù hợp với mức ý nghĩa thống kê $(\mathrm{p}<0.05)$ đồng nghĩa với việc độ tin cây vào mùa mưa là rất cao với giá trị $\mathrm{S}$ rất cao đạt 86 , độ lệch chuẩn $\mathrm{S}$ bằng 39,85, giá trị $\mathrm{Z}$ bằng 2,133 và độ dốc $\mathrm{TS}$ bằng 0,0225 (Hình $4 \mathrm{a}$ ). 


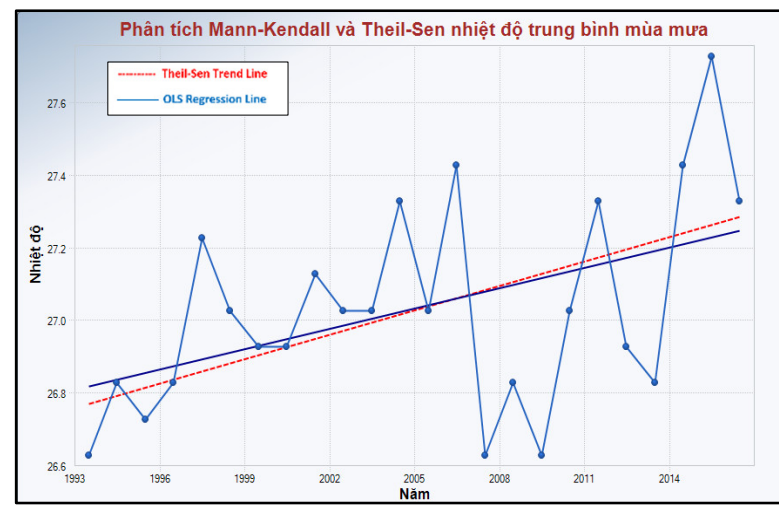

(a)

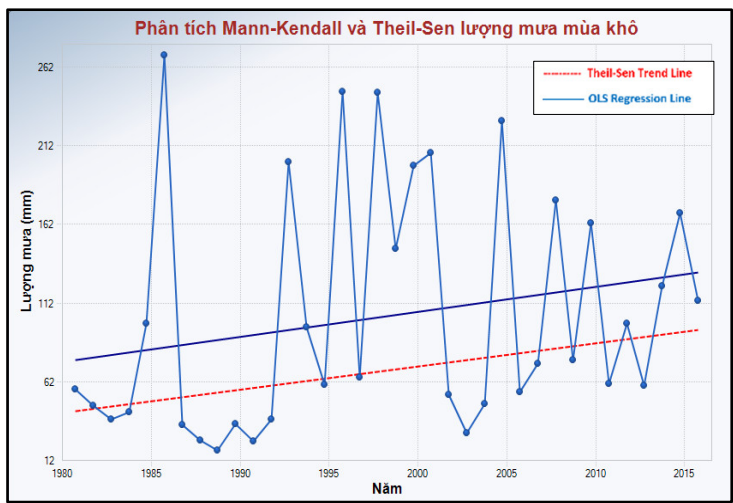

(b)

Hình 4. Xu thế biến đổi nhiệt độ (a) và lượng mưa (b) trung bình năm.

\subsubsection{Xu hướng biến đổi lượng mưa trung bình năm}

Kết quả điểm định cho thấy lượng mưa đang có xu hướng tăng trên địa bàn tỉnh Ninh Thuận (Bảng 3 ). Trong đó có hai tháng có xu hướng giảm là tháng 8 và tháng 9 , các tháng còn lại có xu hướng tăng. Với các tháng tăng, xét về ý nghĩa thống kê chỉ có các tháng 1,3 , 7 và 11 là có giá trị thống kê với chỉ số $p$-value đạt giá trị lần lượt là $0,009,0,042,0,012$ và 0,04 ; giá trị $Z>0$ đồng nghĩa với xu hướng tăng với giá trị $Z$ lần lượt là $2,35,1,733,2,264$, 1,757; giá trị $\mathrm{S}$ tương đối cao và lần lượt bằng $158,121,166,130$ và độ lệch chuẩn $\mathrm{S}$ bằng $66,81,69,23,73,42,73,42,73,42$ và 73,41 . Các tháng có xu hướng tăng lượng mưa là 1,3 , 7 , và 11 thì tháng 11 có chỉ số TS cao nhất bằng 3,761 tương đương với mức tăng lượng mưa là $3,761 \mathrm{~mm} /$ năm, các tháng còn lại với mức tăng lượng mưa $0,0158 \mathrm{~mm} /$ năm (tháng 1 ), $0,092 \mathrm{~mm} /$ năm (tháng 2), và $1,316 \mathrm{~mm} /$ năm (tháng 7 ). Cũng theo kết quả kiểm định lượng mưa trung bình năm đang có xu hướng tăng theo chỉ số TS là $11,01 \mathrm{~mm} / \mathrm{năm}$, kêt quả này rất có ý nghĩa vì độ tin cậy cao với $\mathrm{p}$-value bằng 0,004 . Xem xét đến mùa mưa và mùa khô, kết quả cũng chỉ ra được cả hai mùa có xu hướng tăng với mùa mưa cao hơn mùa khô. Vào mùa mưa, giá trị $\mathrm{S}$ dương với $\mathrm{S}$ bằng 118 , độ lệch chuẩn $\mathrm{S}$ là 73,4 , giá trị $\mathrm{Z}$ đạt $1,594, \mathrm{p}$-value bằng 0,0555 , và độ dốc $\mathrm{TS}$ đạt 2,167 (tương đương tăng 2,167 mm). Vào mùa khô, chỉ số $\mathrm{S}$ dương với giá trị $\mathrm{S}$ bằng 146 , độ lệch chuẩn $\mathrm{S}$ bằng 73,42 , chỉ số $\mathrm{Z}$ bằng 1,975 , và $\mathrm{p}$-value bằng 0,0241 ; với chỉ số này cho thấy vào mùa khô xu hướng tăng lượng mưa rất có ý nghĩa thống kê và thông qua chỉ số TS cho thấy kết quả lượng mưa vào mùa khô có thể tăng 1,476 $\mathrm{mm} /$ năm tương ứng với chỉ số TS là 1,476 (Hình 4b). 
Bảng 2. Kết quả phân tích xu thế biến đổi nhiệt độ trung bình năm.

\begin{tabular}{|c|c|c|c|c|c|c|c|c|c|c|c|c|c|c|c|}
\hline \multirow{2}{*}{ Kết quả kiểm định } & \multicolumn{12}{|c|}{ Tháng } & \multirow{2}{*}{ Cả năm } & \multicolumn{2}{|c|}{ Mùa } \\
\hline & 1 & 2 & 3 & 4 & 5 & 6 & 7 & 8 & 9 & 10 & 11 & 12 & & M.Mura & M.Khô \\
\hline M-K Test Value (S) & 12 & -14 & -9 & 33 & 33 & 8 & 1 & 18 & 55 & 56 & 66 & 54 & 43 & 86 & 34 \\
\hline Critical Value $(0,05)$ & 1,645 & $-1,645$ & $-1,645$ & 1,645 & 1,645 & 1,645 & 1,645 & 1,645 & 1,645 & 1,645 & 1,645 & 1,645 & 1,645 & 1,645 & 1,645 \\
\hline Standard Deviation of S & 40,14 & 40,17 & 40,01 & 39,67 & 40,05 & 40,07 & 39,97 & 40,15 & 40 & 39,84 & 40,18 & 40,21 & 39,72 & 39,85 & 39,92 \\
\hline Z Standardized Value of S & 0,274 & $-0,324$ & $-0,2$ & 0,807 & 0,799 & 0,175 & 0,0 & 0,423 & 1,35 & 1,38 & 1,618 & 1,318 & 1,057 & 2,133 & 0,827 \\
\hline Approximate $\mathrm{p}$-value & 0,392 & 0,373 & 0,421 & 0,21 & 0,212 & 0,431 & 0,5 & 0,336 & 0,0885 & 0,0837 & 0,0529 & 0,0937 & 0,145 & 0,0165 & 0,204 \\
\hline Theil-Sen Slope & 0,00417 & $-0,00596$ & 0,0 & 0,00667 & 0,0202 & 0,0 & 0,0 & 0,00667 & 0,0148 & 0,0143 & 0,0342 & 0,0306 & 0,01 & 0,0225 & 0,00833 \\
\hline Theil-Sen Intercept & 16,6 & 37,41 & 26,5 & 14,74 & $-11,77$ & 28,95 & 28,5 & 15,09 & $-1,987$ & $-1,736$ & $-42,24$ & $-36,14$ & 7,155 & $-18,05$ & 10,5 \\
\hline $95 \%$ LCL of Slope $(0,025)$ & $-0,05$ & $-0,0625$ & $-0,0286$ & $-0,0143$ & $-0,025$ & $-0,0333$ & $-0,0312$ & $-0,025$ & $-0,00909$ & 0,0 & $-0,0073$ & $-0,0167$ & $-0,00753$ & 0,0 & $-0,0127$ \\
\hline 95\% UCL of Slope $(0,975)$ & 0,05 & 0,0333 & 0,0295 & 0,0357 & 0,06 & 0,0431 & 0,0253 & 0,0333 & 0,04 & 0,0333 & 0,0566 & 0,0781 & 0,025 & 0,0364 & 0,0252 \\
\hline
\end{tabular}

Bảng 3. Kết quả phân tích xu thế biến đổi lượng mưa trung bình năm.

\begin{tabular}{|c|c|c|c|c|c|c|c|c|c|c|c|c|c|c|c|}
\hline \multirow{2}{*}{ Kết quả kiểm định } & \multicolumn{12}{|c|}{ Tháng } & \multirow{2}{*}{ Cả năm } & \multicolumn{2}{|c|}{ Mùa } \\
\hline & 1 & 2 & 3 & 4 & 5 & 6 & 7 & 8 & 9 & 10 & 11 & 12 & & M.Mưa & M.Khô \\
\hline M-K Test Value (S) & 158 & 71 & 121 & 106 & 56 & 118 & 166 & -78 & -42 & 102 & 130 & 53 & 196 & 118 & 146 \\
\hline Critical Value $(0,05)$ & 1,645 & 1,645 & 1,645 & 1,645 & 1,645 & 1,645 & 1,645 & $-1,645$ & $-1,645$ & 1,645 & 1,645 & 1,645 & 1,645 & 1,645 & 1,645 \\
\hline Standard Deviation of $\mathrm{S}$ & 66,81 & 60,82 & 69,23 & 70,1 & 70,41 & 73,42 & 73,42 & 73,42 & 73,42 & 73,42 & 73,42 & 73,3 & 73,42 & 73,4 & 73,42 \\
\hline Z Standardized Value of S & 2,35 & 1,151 & 1,733 & 1,498 & 0,781 & 1,594 & 2,247 & $-1,049$ & $-0,558$ & 1,376 & 1,757 & 0,709 & 2,656 & 1,594 & 1,975 \\
\hline Approximate $\mathrm{p}$-value & 0,009 & 0,125 & 0,042 & 0,067 & 0,217 & 0,056 & 0,012 & 0,147 & 0,288 & 0,085 & 0,04 & 0,239 & 0,004 & 0,0555 & 0,0241 \\
\hline Theil-Sen Slope & 0,0158 & 0,0 & 0,092 & 0,18 & 0,692 & 0,958 & 1,316 & $-0,552$ & $-0,638$ & 1,917 & 3,761 & 0,424 & 11,01 & 2,167 & 1,476 \\
\hline Theil-Sen Intercept & $-31,26$ & 0,0 & $-180,8$ & $-353,1$ & -1337 & -1857 & -2576 & 1151 & 1403 & -3697 & -7388 & $-822,6$ & -21273 & -4188 & -2882 \\
\hline $95 \%$ LCL of Slope $(0,025)$ & 0,0 & 0,0 & 0,0 & $-0,0335$ & $-0,764$ & $-0,256$ & 0,201 & $-1,615$ & $-3,186$ & $-1,192$ & $-0,399$ & $-0,775$ & 3,782 & $-0,358$ & 0,0152 \\
\hline $95 \%$ UCL of Slope $(0,975)$ & 0,18 & 0,0 & 0,302 & 0,68 & 2,86 & 2,349 & 2,381 & 0,466 & 1,512 & 5,375 & 7,519 & 2,635 & 20,66 & 4,145 & 3,421 \\
\hline
\end{tabular}


Bảng 4. Kết quả phân tích xu thế biến đổi chỉ số bốc hơi tiềm năng (PET).

\begin{tabular}{|c|c|c|c|c|c|c|c|c|c|c|c|c|c|c|c|}
\hline \multirow{2}{*}{ Kết quả kiểm định } & \multicolumn{12}{|c|}{ Tháng } & \multirow{2}{*}{ Cả năm } & \multicolumn{2}{|c|}{ Mùa } \\
\hline & 1 & 2 & 3 & 4 & 5 & 6 & 7 & 8 & 9 & 10 & 11 & 12 & & M.Mura & M.Khô \\
\hline M-K Test Value (S) & 61 & -1 & -138 & -43 & -4 & 63 & 12 & -68 & 182 & 193 & 106 & 67 & 56 & 247 & -11 \\
\hline Critical Value $(0,05)$ & 1,645 & $-1,645$ & $-1,645$ & $-1,645$ & $-1,645$ & 1,645 & 1,645 & $-1,645$ & 1,645 & 1,645 & 1,645 & 1,645 & 1,645 & 1,645 & $-1,645$ \\
\hline Standard Deviation of S & 58,8 & 58,82 & 58,81 & 58,62 & 58,81 & 58,8 & 58,74 & 58,77 & 58,75 & 58,82 & 58,81 & 58,78 & 58,81 & 58,8 & 58,82 \\
\hline Z Standardized Value of S & 1,02 & 0,0 & $-2,33$ & $-0,716$ & $-0,051$ & 1,054 & 0,187 & $-1,14$ & 3,081 & 3,264 & 1,785 & 1,123 & 0,935 & 4,184 & $-0,17$ \\
\hline Approximate $\mathrm{p}$-value & 0,154 & 0,5 & 0,0099 & 0,237 & 0,48 & 0,146 & 0,426 & 0,127 & 0,00103 & $5,49 \mathrm{E}-04$ & 0,0371 & 0,131 & 0,175 & $1,44 \mathrm{E}-05$ & 0,432 \\
\hline Theil-Sen Slope & 0,219 & 0,0 & $-0,435$ & $-0,132$ & $-0,00588$ & 0,335 & 0,0091 & $-0,392$ & 0,613 & 0,576 & 0,339 & 0,256 & 0,113 & 0,54 & $-0,0143$ \\
\hline Theil-Sen Intercept & $-338,9$ & 101,6 & 1006 & 435,3 & 209,3 & $-476,9$ & 174,2 & 968,1 & -1074 & -1016 & $-560,9$ & -408 & $-75,71$ & $-943,1$ & 181,8 \\
\hline $95 \%$ LCL of Slope $(0,025)$ & $-0,188$ & $-0,374$ & $-0,709$ & $-0,395$ & $-0,858$ & $-0,281$ & $-0,557$ & $-1,185$ & 0,265 & 0,287 & $-0,016$ & $-0,151$ & $-0,087$ & 0,299 & $-0,287$ \\
\hline $95 \%$ UCL of Slope $(0,975)$ & 0,575 & 0,263 & $-0,069$ & 0,326 & 0,568 & 1,019 & 0,578 & 0,288 & 1,049 & 0,783 & 0,648 & 0,665 & 0,324 & 0,758 & 0,231 \\
\hline
\end{tabular}

Bảng 5. Kết quả phân tích xu thế biến đổi độ ẩm trung bình năm.

\begin{tabular}{|c|c|c|c|c|c|c|c|c|c|c|c|c|c|c|c|}
\hline \multirow{2}{*}{ Kết quả kiểm định } & \multicolumn{12}{|c|}{ Tháng } & \multirow{2}{*}{ Năm } & \multicolumn{2}{|c|}{ Mùa } \\
\hline & 1 & 2 & 3 & 4 & 5 & 6 & 7 & 8 & 9 & 10 & 11 & 12 & & M.Mura & M.Khô \\
\hline M-K Test Value (S) & -67 & -41 & -9 & -13 & -45 & 18 & -1 & 41 & -24 & -10 & 43 & 13 & -10 & 5 & -11 \\
\hline Critical Value $(0,05)$ & $-1,645$ & $-1,645$ & $-1,645$ & $-1,645$ & $-1,645$ & 1,645 & $-1,645$ & 1,645 & $-1,645$ & $-1,645$ & 1,645 & 1,645 & $-1,645$ & 1,645 & $-1,645$ \\
\hline Standard Deviation of S & 40,25 & 40,28 & 40,22 & 40,3 & 40,25 & 40,21 & 40,28 & 40,22 & 40,27 & 40,26 & 40,28 & 40,28 & 40,27 & 40,28 & 40,3 \\
\hline Standardized Value of S & $-1,64$ & $-0,993$ & $-0,199$ & $-0,298$ & $-1,093$ & 0,423 & 0,0 & 0,995 & $-0,571$ & $-0,224$ & 1,043 & 0,298 & $-0,224$ & 0,0993 & $-0,248$ \\
\hline Approximate $\mathrm{p}$-value & 0,0505 & 0,16 & 0,421 & 0,383 & 0,137 & 0,336 & 0,5 & 0,16 & 0,284 & 0,412 & 0,149 & 0,383 & 0,412 & 0,46 & 0,402 \\
\hline Theil-Sen Slope & $-0,117$ & $-0,1$ & $-0,00749$ & $-0,0392$ & $-0,0789$ & 0,05 & 0,0 & 0,0578 & $-0,0437$ & $-0,0167$ & 0,135 & 0,0283 & $-0,0125$ & 0,014 & $-0,015$ \\
\hline Theil-Sen Intercept & 306,3 & 271,9 & 89,56 & 153,9 & 234,4 & $-25,62$ & 75,05 & $-39,32$ & 167,1 & 113,6 & $-193,3$ & 18,14 & 100,6 & 51,13 & 104,6 \\
\hline $95 \%$ LCL of Slope $(0,025)$ & $-0,231$ & $-0,258$ & $-0,136$ & $-0,2$ & $-0,22$ & $-0,111$ & $-0,158$ & $-0,0426$ & $-0,283$ & $-0,174$ & $-0,154$ & $-0,158$ & $-0,0886$ & $-0,156$ & $-0,0964$ \\
\hline $95 \%$ UCL of Slope $(0,975)$ & 0,0524 & 0,06 & 0,0925 & 0,19 & 0,0974 & 0,194 & 0,2 & 0,228 & 0,162 & 0,148 & 0,357 & 0,31 & 0,0635 & 0,161 & 0,0861 \\
\hline
\end{tabular}




\subsubsection{Xu hướng biển đổi lượng bốc thoát hơi tiềm năng}

Kết quả phân tích xu thế cho thấy lượng bốc thoát hơi tiềm năng có nhiều biến động với 5 tháng có xu hướng giảm và 7 tháng có xu hướng tăng (Bảng 4). Phân tích bảng 4 có thể thấy từ tháng 2 đến tháng 5 và tháng 8 là các tháng có xu hướng giảm với giá trị $S$ lần lượt là $-1,-138,-43,-4$, và -68 ; độ lệch chuẩn $\mathrm{S}$ lần lượt là $58,82,58,81,58,62,58,8$, và 58,77 ; chỉ số $Z$ đạt lần lượt là $0,-2,33,-0,716,-0,051$, và $-1,14$; chỉ số $p$-value lần lượt là $0,5,0,00992$, $0,237,0,48$, và 0,127 ; xét về giá trị thống kê thì tháng 3 chỉ số $\mathrm{p}$-value cho thấy có ý nghĩa thống kê hơn các tháng khác. Bên cạnh đó, kết quả độ dốc TS cho thấy lượng bốc thoát hơi tiềm năng giảm ở tháng 3 là $0,435 \mathrm{~mm} /$ năm, tháng 4 là $0,132 \mathrm{~mm} /$ năm, tháng 5 là 0,00588 $\mathrm{mm} / \mathrm{năm}$, tháng 8 là $0,392 \mathrm{~mm} /$ năm. Đối với các tháng có xu hướng tăng là tháng 1 , tháng 6 , tháng 7 , tháng 9 đến tháng 12 thì giá trị $\mathrm{S}$ dao động trong khoảng 12 đến 193; độ lệch chuẩn của các tháng năm trong khoảng 58,6 đến 58,7 ; chỉ số $Z$ dương, cao nhất là tháng 9 và tháng 10 , tháng có ý nghĩa thống kê là tháng 9,10 và tháng 11 với $\mathrm{p}$-value lần lượt là 0,0013 , 0,000549 , và 0,0371 ; Tháng 10 là tháng có giá trị cao nhất trong các tháng còn lại với hệ số TS tăng 0,576 tương ứng với tăng $0,576 \mathrm{~mm} / \mathrm{năm}$, với giá trị $\mathrm{S}$ cao nhất 193 , độ lệch chuẩn đạt 58,82, giá trị $Z$ đạt 3,264 (Hình $5 b$ ). Lượng bốc thoát hơi tiềm năng năm cũng có xu hướng tăng với chỉ số $Z$ dương là 0,935 , chỉ số TS là 0,113 tương ứng với tăng thêm 0,113 $\mathrm{mm} /$ năm. Ngoài ra, xét theo yếu tố mùa thì lượng bốc thoát hơi tiềm năng của mùa mưa có xu hướng tăng và mùa mưa có xu hướng giảm. Vào mùa mưa, kết quả tính cho thấy chỉ số $Z$ dương đạt 4,184 , giá trị $\mathrm{S}$ rất cao là 247 , độ lệch chuẩn $\mathrm{S}$ đạt 58,81 và chỉ số $\mathrm{p}$-value đạt ý nghĩa thống kê là 0,000144 ; ngoài ra, kết quả phân tích TS đạt 0,54 , chỉ số này cho thấy lượng bốc hơi tiềm năng tăng $0,54 \mathrm{~mm} /$ năm (Hình $5 \mathrm{a}$ ).

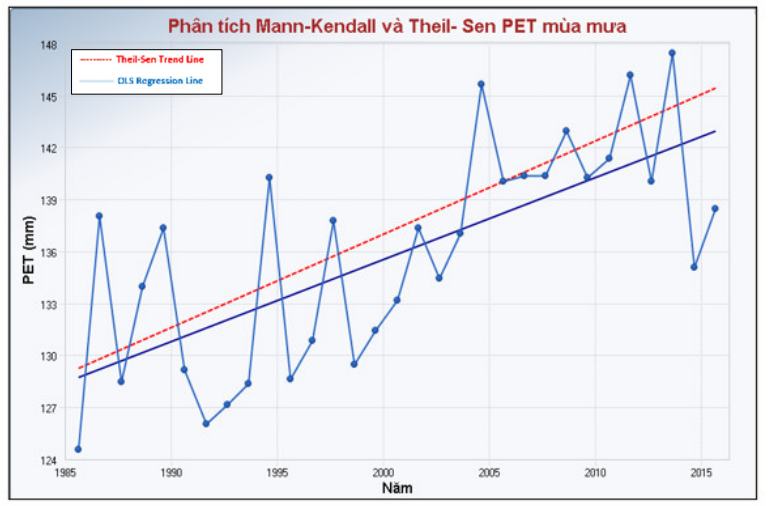

(a)

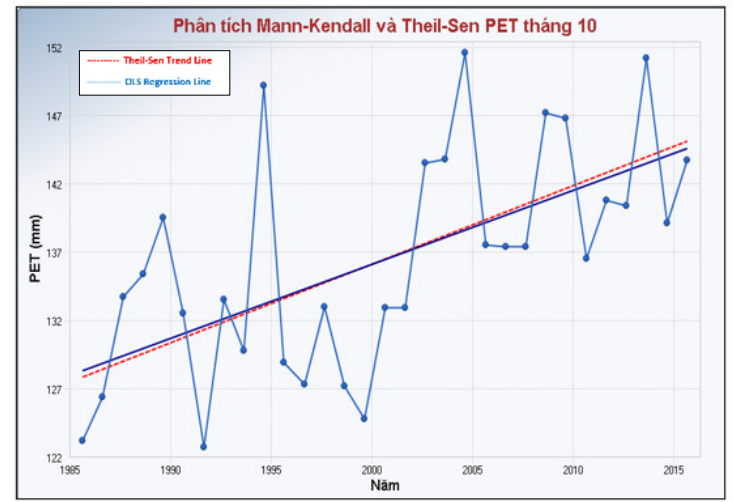

(b)

Hình 5. Xu thế biến đổi lượng bốc thoát hơi tiềm năng mùa mưa (a) và tháng 10 (b).

\subsubsection{Xu hướng biến đổi độ ẩm trung bình năm}

Độ ẩm trung bình năm giai đoạn nghiên cứu có sự biến động trong năm và theo mùa. Kết quả phân tích bảng 5 cho thấy, trong năm độ ẩm có xu hướng giảm vào các tháng $1-5$, tháng 7, tháng 9-10; các tháng còn lại có xu hướng tăng. Với các tháng giảm, giá trị $\mathrm{S}$ âm dao động từ -67 đến -1 , chỉ số $Z$ âm với dao động trong khoảng $-0,5$ đến $-1,6$; độ dốc $T S$ cho thấy vào các tháng giảm độ ẩm có thể giảm từ 0,00749 đến 0,1 . Các tháng có xu hướng tăng là tháng 6 , tháng 8 , tháng 11 , và tháng 12 với giá trị $\mathrm{S}$ luôn dương $(\mathrm{S}>0)$; độ lệch chuẩn $\mathrm{S}$ của các tháng động từ 40,2 đến 40,3 ; chỉ số $\mathrm{Z}$ lần lượt của các tháng lần lượt là 0.423 , $0,995,1,034$ và 0,298 và độ tin cậy của các tháng tăng trong khoản 0,1 đển 0,4 , với chỉ số $\mathrm{p}-$ value lớn hơn 0,05 nên ý nghĩa thống kê không nhiều. Xét mức độ tăng giảm độ ẩm trung bình theo độ dốc TS, có thể thấy trong năm chỉ có bốn tháng có xu hướng tăng độ ẩm rõ rệt đó là tháng 6 , tháng 8 , tháng 11 và tháng 12 với mức tăng $(\%)$ lần lượt là $0,05,0,0578,0,135$, 0,0283 ; Kết quả phân tích TS các tháng giảm cũng cho thấy từ tháng $1-5$, tháng 9-10 với 
mức giảm lần lượt trong một năm là $0,117 \%, 0,1 \%, 0,00749 \%, 0,0392 \%, 0,0789 \%, 0,0437 \%$, $0,0167 \%$, trong đó tháng có xu hướng giảm mạnh là tháng 1 (Hình 6). Xét theo trung bình năm và theo mùa, độ ẩm có xu hướng tăng vào mùa mưa, giảm vào mùa khô và trung bình năm. Theo bảng 5 , giá trị $S$ của mùa mưa là 5 còn mùa khô là -11 và năm là -10 , chỉ số $Z$ của mùa mưa là 0,0993 , mùa khô là $-0,248$ và trung bình năm là $-0,224$; về ý nghĩa thống kê cả mùa mưa, mùa khô và trung bình năm chỉ vào khoảng 0.4 lớn hơn mức ý nghĩa thống kê $\mathrm{p}$-value $(\mathrm{p}<0,05)$. Chỉ số độ dốc $\mathrm{TS}$ cho thấy mỗi năm độ ẩm tăng thêm $0,014 \%$ vào mùa mưa, mùa khô giảm $0,015 \%$ và cả năm giảm $0,0125 \%$.

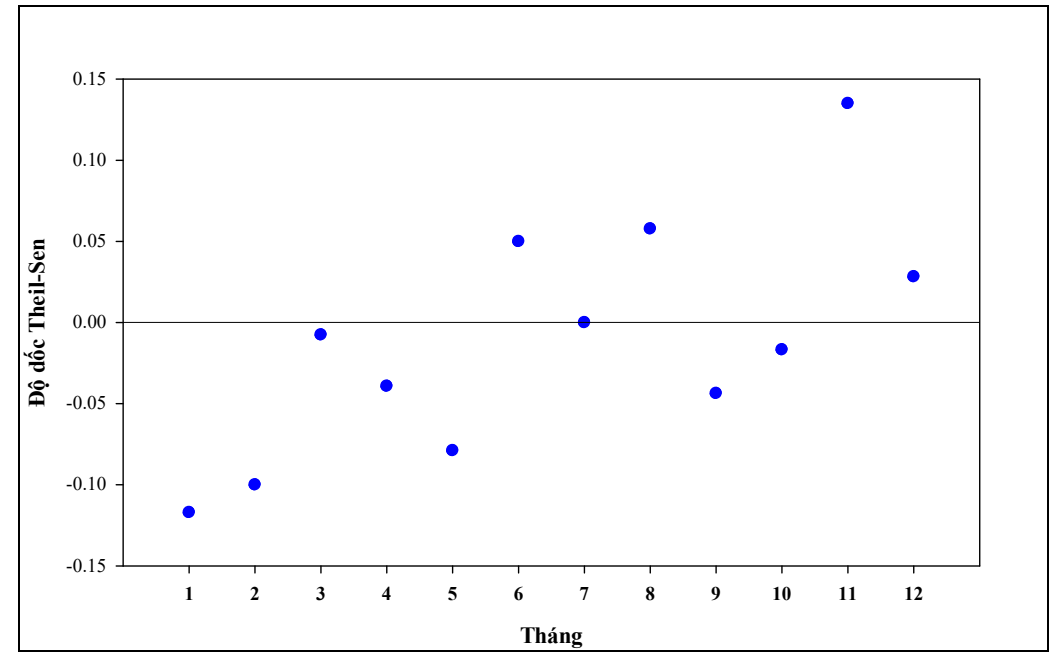

Hình 6. Độ dốc TS độ ẩm trung bình năm giai đoạn 1993 -2016.

\subsection{Dự tính xu thế biến đổi đặc điểm khi hậu ở Ninh Thuận}

Dựa vào kết quả phân tích MK và TS, kết quả dự tính đặc điểm khí hậu tỉnh Ninh Thuận thông qua giá trị trung bình năm của nhiệt độ, lượng mưa, bốc thoát hơi tiềm năng và độ ẩm.

\subsubsection{Dự tính xu thế biến đổi nhiệt độ và lượng mưa năm}

Với mức tăng trung bình năm là $0,01^{\circ} \mathrm{C} /$ năm nhiệt độ trung bình năm ở Ninh Thuận đang có xu hướng tăng và dự tính trung bình 10 năm nhiệt độ trung bình năm tăng thêm $0.1^{\circ} \mathrm{C}$, tăng $0,2^{\circ} \mathrm{C}$ cho mùa mưa, và $0,08^{\circ} \mathrm{C}$ cho mùa khô. Với nhiệt độ trung bình năm 2016 là $27,5^{\circ} \mathrm{C}$, dự tính đến năm 2026 nhiệt độ trung bình tăng lên $27,6^{\circ} \mathrm{C}$, năm 2056 nhiệt độ dự tính tăng $27,9^{\circ} \mathrm{C}$, và đến cuối thế kỷ 21 nhiệt độ trung bình tăng lên $28,3{ }^{\circ} \mathrm{C}$; Vào mùa mưa nhiệt độ trung bình tăng thêm $0,8^{\circ} \mathrm{C}$ đến cuối thể kỷ 21 và nhiệt độ trung bình mùa khô tăng $0,7^{\circ} \mathrm{C}$ (Hình $\left.7 \mathrm{a}\right)$.

Kết quả nghiên cứu cho thấy lượng mựa trong giai đoạn nghiên cứu tăng trung bình $11,01 \mathrm{~mm} /$ năm dự tính lượng mưa, dự tính đến năm 2026 tăng lên 183,8 mm (năm 2016 là $73,7 \mathrm{~mm}$ ), năm 2056 lượng mưa đạt khoảng 514 mm, và cuối thể kỷ lượng mưa đạt đến 954.5 mm tăng 880,8 mm so với năm 2016; Vào mùa mưa lượng mưa tăng với năm 2016 lượng mưa đạt 191,9 mm đến năm 2056 tăng lên 268,6 mm, và đến cuối thể kỷ lượng mưa tăng lên đến $365,3 \mathrm{~mm}$; Vào mùa khô lượng mưa tăng thấp nhất với trung bình tăng $1,5 \mathrm{~mm} / \mathrm{năm}$, năm 2016 lượng mưa đạt 113,4 mm, đến năm 2056 lượng mưa tăng lên 173,4 mm, và đến cuối thể kỷ lượng mưa đạt khoảng 231,5 mm (Hình 7b). 


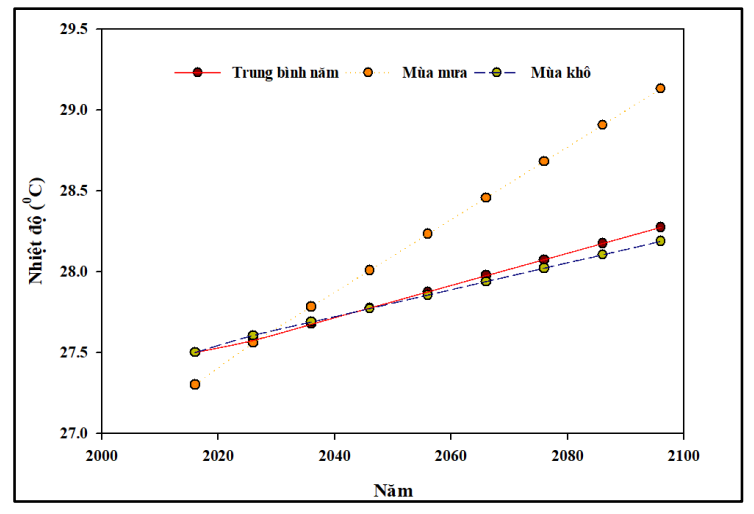

(a)

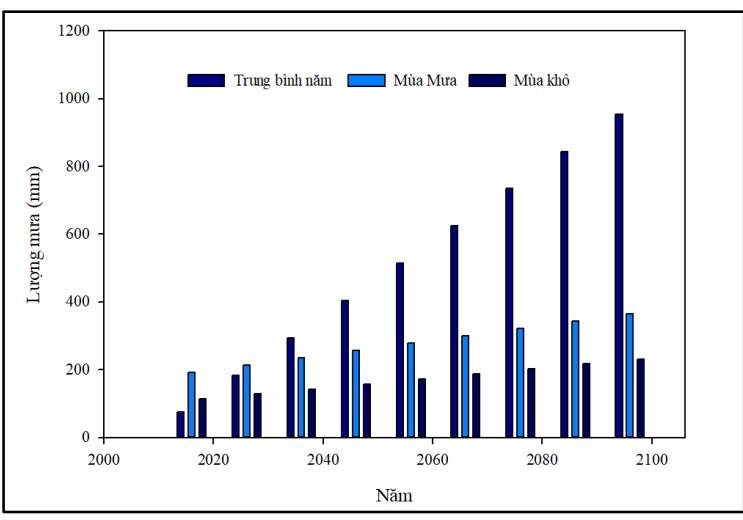

(b)

Hình 7. Dự tính xu thế biển đổi nhiệt độ $(\mathrm{a})$, và lượng mưa (b).

\subsubsection{Dự tính xu thế biến đổi bốc thoát hơi tiềm năng và độ ẩm năm}

Lượng bốc thoát hơi tiềm năng ở Ninh Thuận có xu hướng tăng theo trung bình năm, mùa mưa và mùa khô có xu hướng giảm. Độ bốc thoát hơi tiềm năng trung bình năm tăng $0,113 \mathrm{~mm} /$ năm và có xu hướng tăng từ 2016 đến cuối thế kỷ 21 ; Tuy nhiên, vào mùa mưa lượng bốc thoát hơi tiềm năng tăng cao nhất với trung bình tăng thêm $0,54 \mathrm{~mm} / \mathrm{năm}$. Kết quả dự tính cho thấy vào mùa mưa lượng bốc thoát hơi tiềm năng tăng từ 138,5 mm năm 2016 lền đến $160,1 \mathrm{~mm}$ giữa thế kỷ 21 , và cuối thế kỷ 21 tăng lên $181,7 \mathrm{~mm}$; vào mùa khô lượng bốc hơi tiềm năng có xu hướng giảm khoảng $0,014 \mathrm{~mm}$, dự tính đến năm 2056 lượng bốc hơi tiềm năng giảm từ 145,4 (2016) xuống còn 144,8 mm và đến năm 2096 lượng bốc hơi tiềm năng có thể giảm xuống còn $144,3 \mathrm{~mm}$ (Hình $8 \mathrm{a}$ ).

Độ ẩm trung bình năm 2016 của Ninh Thuận là 78,4 \% với dự tính trung bình năm giảm $0,013 \%$ thì đến năm 2056 độ ẩm giảm xuống còn 77,9\% và dự tính đến cuối thập kỷ độ ẩm toàn tỉnh chỉ còn khoảng $77,4 \%$; Vào mùa khô, độ ẩm của vùng có xu hướng giảm với 0,02 $\%$, dự tính đến năm 2056 độ ẩm giảm từ $77,1 \%$ xuống còn $76,5 \%$ và đến cuối thế kỷ 21 giảm xuống còn $75,9 \%$; Cùng với đó, dự tính vào mùa mưa độ ẩm ở khu vực tăng lên với mức tăng trung bình là $0,014 \%$ kết quả dự tính đến giữa thế kỷ 21 độ ẩm có thể tăng đến $82,9 \%$ và cuối thế 21 độ ẩm trung bình mùa mưa tăng lên khoảng $83,4 \%$ cao hơn so với trung bình năm và mùa khô (Hình $8 \mathrm{~b})$.

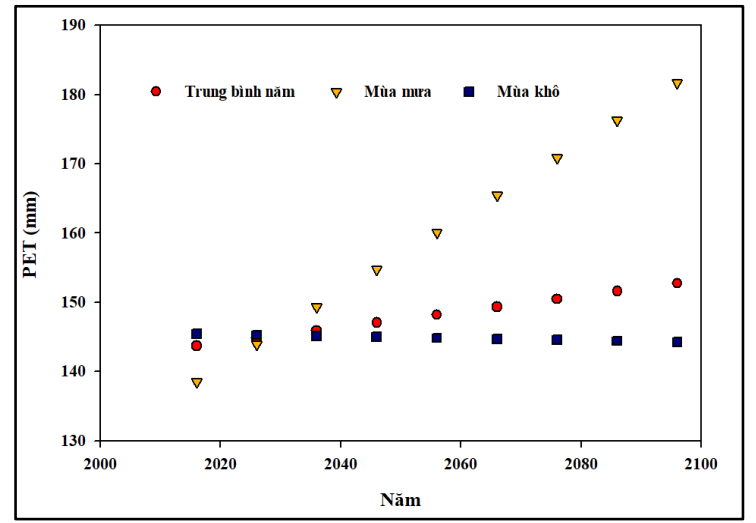

(a)

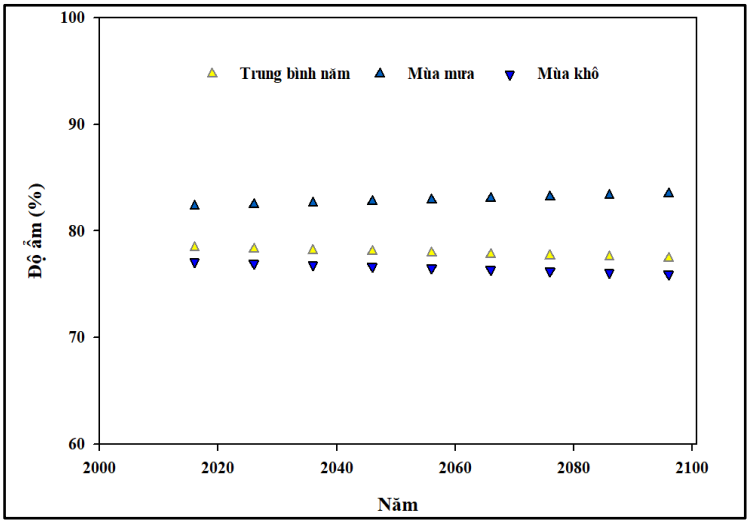

(b)

Hình 8. Dự tính xu thế biển đổi bốc thoát hơi tiềm năng (a), và độ ẩm (b).

Có thể nói trong bối cảnh hạn hán, kết quả dự tính cũng cho thấy phần nào xu hướng gia tăng nhiệt độ, lượng mưa, độ bốc thoát hơi tiềm năng, và độ ẩm. Bên cạnh đó, nếu các kết quả dự tính so sánh với kịch bản Biến đổi khí hậu của Bộ Tài nguyên và môi trường cho khu vực Ninh Thuận cho thấy kết quả nghiên cứu đang có xu hướng tăng trong xu thế tăng của 
kịch bản năm 2016 [29]. Nhưng kết quả dự tính các chỉ số còn khiêm tốn nên thấp hơn các chỉ số của kịch bản đã đề cập. Nguyên nhân sự khác biệt về kết quả dự tính của nghiên cứu và của kịch bản có sự khác nhau về giá trị đầu vào. Theo Nguyễn Minh Kỳ thì sự khác biệt giữa cách tính trong $\mathrm{MK}$ và $\mathrm{TS}$ với kịch bản $\mathrm{BĐKH}$ phụ thuộc vào biến đầu vào, với phương pháp này chủ yếu là đơn biến còn với kịch bản của Bộ Tài Nguyên và Môi trường thường xây dựng dựa trên yếu tố đa biến [27].

\section{Kết luận}

Phân tích MK và TS đã đánh giá được xu thế biến đổi và dự tính được xu thế của các yếu tố nhiệt độ, lượng mưa, lượng bốc thoát hơi tiềm năng, và độ ẩm ở khu vực Ninh Thuận. Kết quả đã cho thấy trong giai đoạn nghiên cứu ở Ninh Thuận nhiệt độ trong năm giảm ở tháng 2 và 3 tăng ở các tháng còn lại với tăng cao nhất là $0,01^{\circ} \mathrm{C} /$ năm. Lượng mưa giảm vào các tháng 8 và 9 với mức giảm cao nhất là $0,6 \mathrm{~mm} /$ năm, tăng ở các tháng còn lại trong đó tăng cao nhất là $3.7 \mathrm{~mm} /$ năm ở tháng 11 . Lượng bốc thoát hơi tiềm năng cũng có biến động tăng ở các tháng $1,6,7,9,10,11$ và 12 với tăng cao nhất là $0,6 \% /$ năm và giảm ở các tháng còn lại với mức giảm nhiều nhất là $0,4 \% /$ năm. Độ ẩm cũng có xu hướng giảm với tám tháng giảm và bốn tháng tăng với tăng cao nhất là $0,1 \% /$ năm. Bên cạnh đó, dự kết quả dự tính xu thế đã cho thấy nhiệt độ trung bình năm tăng thêm $0,8^{\circ} \mathrm{C}$ đến cuối thể kỷ 21 , mùa mưa tăng $1,8^{\circ} \mathrm{C}$, và mùa khô là $0,7^{\circ} \mathrm{C}$. Lượng mưa tăng đến cuối thế kỷ với lượng mưa năm tăng thêm $880,8 \mathrm{~mm}$, lượng mưa mùa mưa tăng $173,4 \mathrm{~mm}$ và lượng mưa mùa khô tăng $118,1 \mathrm{~mm}$. Kết quả dự tính xu thế tăng lượng bốc thoát hơi tiềm năng cũng cho thấy tăng ở trung bình năm và mùa mưa trong khi mùa khô đang có xu hướng giảm với trung bình $1,14 \mathrm{~mm}$ đến cuối thế kỷ 21. Độ ẩm dự tính tăng vào mùa mưa, kết quả cho thấy đến cuối thế kỷ 21 độ ẩm tăng thêm $1,12 \%$ so với giai đoạn nghiên cứu.

Nghiên cứu đã phân tích và dự tính được những đặc điểm cơ bản về nhiệt độ, lượng mưa, độ ẩm, và lượng bốc thoát hơi tiềm năng. Kết quả nghiên cứu đóng góp thêm cơ sở khoa học cho việc xây dựng các kế hoạch, giải pháp tích ứng trong bối cảnh hạn hán tại tỉnh Ninh Thuận trong tương lai. Bên cạnh đó dù kết quả dự tính còn thấp hơn kịch bản Biến đổi khí hậu của Bộ Tài nguyên và Mồi trường nhưng cũng đã cho thấy có sự giống nhau về mức độ tăng nhiệt độ và lượng mưa trung bình đến cuối thế kỷ 21 .

Đóng góp của tác giả: Xây dựng ý tưởng nghiên cứu: N.H.T., T.T.C.; Lựa chọn phương pháp nghiên cứu: N.HT., T.T.C.; Xử lý số liệu: N.H.T.; Tính toán số liệu: N.H.T.; Viết bản thảo bài báo: N.H.T.; Chỉnh sửa bài báo: N.H.T., T.T.C.

Lời cam đoan: Tập thể tác giả cam đoan bài báo này là công trình nghiên cứu của tập thể tác giả, bài nghiên cứu này chưa được công bố ở bất kỳ tạp chí trong nước và quốc tế nào hết. Tập thể tác giả cam đoan không sao chép nghiên cứu trước đây và không có sự tranh chấp lợi ích trong nhóm.

\section{Tài liệu tham khảo}

1. Tuấn, N.Đ.; An, N.L. Nghiên Cứu Các Yếu Tố Gây Hạn Hán, Chỉ Tiêu, Phân Cấp Hạn ở Tỉnh Ninh Thuận-Bình Thuận và Giải Pháp Phòng, Chống, Giảm Thiểu. Tạp Chí Khoa Học Kỹ Thuật Thủ Lợi Và Môi Trường 2016, 30, 132.

2. Tuấn, N.Đ.; Tuy, B.V.; Phùng, N.K. Tác Động Của Biến Đổi Khí Hậu Đến Lĩnh Vực Nông Nghiệp ở Ninh Thuận và Giải Pháp Tương Úng. Tạp Chí Tài Nguyên Và Môi Truòng 2012, 23-26.

3. Chanh, B.V.; Trường, N.H. Khái Quát Đặc Điểm Khí Hậu Thủy Văn ở Tỉnh Ninh Thuận. Tạp chí Khí tượng Thủy văn 2016, 669, 16-20. 
4. Năm, T.T.; Minh P.T.; Tuyết B.T. Nghiên cứu Đặc điểm Khí hậu tỉnh Ninh Thuận. Tạp chí Khi tuoơng Thủy văn 2018, 691, 21-29.

5. Trường, N.H. Úng Dụng Các Biện Pháp Truyền Thống và Khoa Học Kỹ Thuật Mới Nhằm Khai Thác, Bảo vệ Tài Nguyên Đất và Nước, Góp Phần Phòng Chống Hạn ở Xã Phước Nam Tỉnh Ninh Thuận. Tạp Chí Khí Tương Thủ Văn 2008, 45-50.

6. Bình, Đ.; Hoàn, P. Tình Trạng Thiếu Nước Trong Mùa Khô Hạn tại Ninh Thuận. Thông Tin Khoa Học Công Nghệ Ninh Thuận 2012.

7. Thornthwaite, C.W. An Approach toward a Rational Classification of Climate. Geogr. Rev. 1948, 38, 55. https://doi.org/10.2307/210739.

8. Adhikari, A.; Mainali, K.P.; Rangwala, I.; Hansen, A.J. Various Measures of Potential Evapotranspiration Have Species-Specific Impact on Species Distribution $\begin{array}{lllll}\text { Models. } & \text { Ecol. } & \text { Model. } & \text { 2019, } & 414,\end{array}$ https://doi.org/10.1016/j.ecolmodel.2019.108836.

9. Schrier, G. van der; Jones, P.D.; Briffa, K.R. The Sensitivity of the PDSI to the Thornthwaite and Penman-Monteith Parameterizations for Potential Evapotranspiration. J. Geophys. Res. Atmos. 2011, 116, D03106. https://doi.org/10.1029/2010JD015001.

10. Yang, Q.; Ma, Z.; Zheng, Z.; Duan, Y. Sensitivity of Potential Evapotranspiration Estimation to the Thornthwaite and Penman-Monteith Methods in the Study of Global Drylands. Adv. Atmospheric Sci. 2017, 34, 1381-1394. https://doi.org/10.1007/s00376-017-6313-1.

11. Mohammed, R.; Scholz, M. Impact of Evapotranspiration Formulations at Various Elevations on the Reconnaissance Drought Index. Water Resour. Manag. 2017, 31, 531-548. https://doi.org/10.1007/s11269-016-1546-9.

12. McCabe, G.J.; Wolock, D.M. Detectability of the Effects of a Hypothetical Temperature Increase on the Thornthwaite Moisture Index. J. Hydrol. 1991, 125, 2535. https://doi.org/10.1016/0022-1694(91)90081-R.

13. Pereira, A.R.; Pruitt, W.O. Adaptation of the Thornthwaite Scheme for Estimating Daily Reference Evapotranspiration. Agric. Water Manag. 2004, 66, 251-257. https://doi.org/10.1016/j.agwat.2003.11.003.

14. Mann, H.B. Nonparametric Tests Against Trend. Econometrica 1945, 13, 245-259. https://doi.org/10.2307/1907187.

15. Kendall, M.G. Rank Correlation Methods; Griffin: London, 1975.

16. Theil, H. A Rank-Invariant Method of Linear and Polynomial Regression Analysis 1, 2, 3. Confidence Regions for the Parameters of Polynomial Regression Equations. In Proceedings KNAW 1950, 53,386-392.

17. Sen, P.K. Estimates of the Regression Coefficient Based on Kendall's Tau. J. Am. Stat. Assoc. 1968, 63, 1379-1389. https://doi.org/10.2307/2285891.

18. Bhuyan, Md. D.I.; Islam, Md. M.; Bhuiyan, Md. E.K. A Trend Analysis of Temperature and Rainfall to Predict Climate Change for Northwestern Region of Bangladesh. Am. J. Clim. Change 2018, 07, 115-134. https://doi.org/10.4236/ajcc.2018.72009. 
19. Ragatoa, D.S.; Ogunjobi, K.O.; Okhimamhe, A.A.; Francis, S.D.; Adet, L. A Trend Analysis of Temperature in Selected Stations in Nigeria Using Three Different Approaches. OALib 2018, 05, 1-17. https://doi.org/10.4236/oalib.1104371.

20. Karanja, A.; Ondimu, K.; Recha, C. Analysis of Temporal Drought Characteristic Using SPI Drought Index Based on Rainfall Data in Laikipia West Sub-County, Kenya. OALib 2017, 04, 1-11. https://doi.org/10.4236/oalib.1103765.

21. Altın, T.B.; Barak, B.; Altın, B.N. Change in Precipitation and Temperature Amounts over Three Decades in Central Anatolia, Turkey. Atmospheric Clim. Sci. 2012, 02, 107-125. https://doi.org/10.4236/acs.2012.21013.

22. Bera, S. Trend Analysis of Rainfall in Ganga Basin, India during 1901-2000. Am. J. Clim. Change 2017, 06, 116-131. https://doi.org/10.4236/ajcc.2017.61007.

23. Byakatonda, J.; Parida, B.P.; Moalafhi, D.B.; Kenabatho, P.K. Analysis of Long Term Drought Severity Characteristics and Trends across Semiarid Botswana Using Two Drought Indices. Atmospheric Res. 2018, 213, 492-508. https://doi.org/10.1016/j.atmosres.2018.07.002.

24. Güner Bacanli, Ü. Trend Analysis of Precipitation and Drought in the Aegean Region, Turkey: Trend Analysis of Precipitation and Drought. Meteorol. Appl. 2017, 24 (2), 239-249. https://doi.org/10.1002/met.1622.

25. Tín, N.V. Đánh Giá Xu Thế Biến Đổi Của Lượng Mưa Thời Đoạn Lớn Nhất Khu Vực Thành Phố Hồ Chí Minh Giai Đoạn 1971-2016 Bằng Kiểm Định Phi Tham Số Mann-Kendall. Tạp Chí Khí Tương Thủ Văn 2017, 638, 52-55.

26. Thành, N.Đ.; Tân, P.V. Kiểm nghiệm phi tham số xu thê biển đổi một số yếu tố khí tượng cho giai đoạn 1961 -2007. Tap Chi Khoa Hoc ĐHQGHN Khoa Hoc Tư Nhiên Và Công Nghệ 2012, 1-8.

27. Kỳ, N.M. Phân tích và đánh giá lượng mưa trong xu hướng Biến đổi khí hậu giai đoạn 1979-2011 ở thành phố Đà Nẵng. Tạp Chí Khoa Học Trường Đại Học Giang 2016, 12, 110-117.

28. Hằng, P.T.T. Xu thế Biến đổi khí hậu và dòng chảy lưu vực sông Ba. Tạp Chí Các Khoa Học Về Trái Đất 2014, 36, 131-400.

29. Bộ Tài nguyên và Môi trường. Kịch bản Biến đổi khí hậu và nước biển dâng cho Việt Nam. Nhà xuất bản Tài nguyên Môi trường và Bản đồ Việt Nam: Hà Nội, Việt Nam, 2016.

\title{
Research trend of change and future projected climate in Ninh Thuan province
}

\author{
Nguyen Hoang Tuan ${ }^{1 *}$, Truong Thanh Canh $^{2}$ \\ ${ }^{1}$ University of Science, VNU.HCM, Vietnam; nhtuansg@gmail.com \\ ${ }^{2}$ University of Science, VNU.HCM, Vietnam; ttcanh@hcmus.edu.vn
}

Abstract: The study's objective is to analyze and estimate the trend of climatic factors of Ninh Thuan province. The non-parametric test method used in this study is Mann-Kendall and TheilSen analysis. The study results showed that the average temperature increases with an increase of $0.01{ }^{\circ} \mathrm{C}$, average annual precipitation increases by $11.01 \mathrm{~mm}$, potential evaporation increases $0,013 \mathrm{~mm}$, and annual average humidity decreases by $0.01 \%$. The forecast results showed that by the end of the $21 \mathrm{st}$ century, the annual average temperature increased $0,8{ }^{\circ} \mathrm{C}$, rainfall increased by $880.8 \mathrm{~mm}$. The potential evaporation rate increased by $9.04 \mathrm{~mm}$, and the humidity 
decreased by $1.0 \%$. Research results have contributed to the database for applying nonparametric tests in the fields of natural resources and the environment. The research has also provided the locality with a research tool on climate characteristics, helping agencies and organizations better understand the climate characteristics, understand the climate characteristics better, and have strategies and solutions to adapt and mitigate the impacts of drought on the local Socio-Economic.

Keywords: Temperature; Precipitation; Humidity; Potential evaporation; Mann-Kendall; Theil-Sen; 